\title{
Imparcialidade Jurisdicional Versus Discricionariedade Administrativa ${ }^{1}$
}

LUIZ R. NuÑES PADILLA

Professor da Faculdade de Direito da UFRGS. Procurador do Estado

\section{SUMÁRIO}

1. Poder Executivo; 1.1. Poder e Estado; 1.2. Poder Executivo; 1.3. Poder Executivo Federal: a) Presidencia da República; b) Vice-Presidência; c) Ministros de Estado; d) Órgāos da Administração Direta e Indireta; e) Conselho da Republica: if Conselho de Defesa Nacional; 2. Discricionariedade Administrativa $x$ Imparcialidade Jurisdicional: 2.1. Medidas Provisórias; 2.2. Controle Judicial; 2.3. Politica e Poder.

\section{RESUMO}

Comparação entre a atividade jurisdicional administrativa. Discricionariedade Administrativa versus Imparcialidade Jurisdicional. A tiva versus Imparcialidade Jurisdição no conceito de jurisdiça, de Chiovenda a Micheli, passando pelos mestres peninsulares do processo. O Poder Executivo após a Constituição de 1988 , e as peculiaridades nacionais como o descontrole dos mandatários e o caro hábito de passar o poder ao Vice-Presidencaro habilo de passar o poder ao Vriticestente quando das viagens do titular. Crítica ao sistema hibrido, presidencialista mas adotando medidas provisórias, instituto dos sistemas parlamentaristas onde o controle politico impede que o Executivo usurpe a função legislativa do Congresso. Sugere maior atuação do Judiciário diante das medidas provisórias inconstitucionais na origem por não configurarem "casos urgenna origem por nao configurarem "casos tes". Trabalho multidisciplinar comparando trativa.

\section{PODER EXECUTIVO}

Antes de comparar as decisōes administrativas e judiciais, cumpre relembrar alguns aspectos do Poder Executivo cuja estrutura não é vivenciada no dia a dia dos operadores do direito.

\subsection{Poder e Estado}

Poder deriva do verbo latino "posse".

No Direito Público, exprime os órgãos ou instituicōes a quem se confere uma parcela da soberania do Estado, permite-lhes autoridade para exercer as funções atribuidas pela ordem politico-administrativa, juridicamente organizada.

Desde a "potestas" ou "imperium" do Direito Romano, onde a chefia do Estado possuia autoridade suprema, a concepção de poder evoluiu. 0 poder do Estado origina-se do povo "que perce por meio de representantes eleitos" (CF. art. $1^{\circ}$, parágrafo único). Lamentavelmente, inexistem mecanismos eficazes para o controle do mandato popular. Ao contrário do mandato civil, que pode ser revogado pelo mandante quando o mandatário decai de sua confiança (arts $1.300,1.316$ e ss. do Código Civill, o mandato popular ou politico, conta unicamente com os instrumentos previst instrumentos previstos no art. 14 da Constiturção Federal para "controle" do mandatário. O voto, o plebiscito, o referendo, e a iniciativa popular são os mecanismos constitucionais, este último uma importante inovação da Constituição Federal de 1988 possibilitando a apresentação de projeto de lei à Câmara dos Deputados por eleitores que representem, no mínimo, um por cento dos alistados no pais (art. 61, pará- grafo $2^{\circ}, \mathrm{CF}$ ). São mecanismos insuficientes, pois o eleitor não tem como controlar seu representante $^{2}$, até por que 0 voto é secreto. O único mecanismo de controle consiste em não votar mais nos mandatários que perdem a confiança, mas o poder econômico é tão influente nas eleições que esse fator chega a perder a significação.

Todos esses procedimentos, e muito mais, estão previstos na Constituiçāo que, como sintetizou Rui Barbosa, “... não se adotam para tiranizar, mas para escudar a consciência dos povos." 3

\subsection{Poder Executivo}

A Constituição Federal adota a tripartição dos poderes, "harmônicos e independentes entre si". Essa concepção deve-se a Montesquieu, visando reduzir a possibilidade de arbitrio, ao dividir seus poderes em vários órgãos. Ao mesmo tempo, o menor encargo de atribuicão permitiria um exercicio mais eficaz. A tripartição é observada nas esferas federal e estaduais; os municipios brasileiros, ao contrário do que se observa em alguns paises da Commom Law, não possuem Poder Judiciário próprio. Falam em outros "poderes", tão ou mais fortes que o do Estado, sugerindo aquela poderosa, inocultável e inocultada influência da Igreja e de outras agremiaçóes religioso-filosóficas, como a maçonaria, os rosa-cruz, que paulatinamente foram cedendo terreno para os meios de comunicação cuja influência tem sido observada sobre os poderes executivo e legislativo, e agora passam a pressionar o judiciario, em constante critica a decisōes e procedimentos jurisdicionais.

Essa tripartição de poderes desafia criticas. Cesar Saldanha de Souza Jr., Procurador da República, Doutor em Direito Constitucional pela Usp, e professor da Ufrgs, manilesta há mais de um lustro, desde a "Crise da Democracia no Brasil" (Forense), a ineficácia decorrente da tripartição dos poderes. Com a veemência que the é peculiar, enfatizou os vinculos e simpatias do nobre ideólogo francês com o liberalismo. Para Montesquieu, separar os poderes executivo e legislativo serviria ao propósito de reduzir a esfera de atuação e intervenção estatal na vida do cidadãos, porque a separação gera a inoperân- cia de um e outro. O sistema de Governo Parlamentarista resolve o impasse. Impóe sadia interdependência entre os poderes Executivo e Legislativo ao governar o Estado. Separa as funcooes de Chefia de Estado para serem exercidas por outro órgão, distinguindo a natural discorntra contra as clausulas petreas e os valores permanentes da Pátria, personificados no Chefe de Estado. Com exceção de breve e anômalo periodo parlamentarista imposto em 1961, o Brasil republicano adotou o presidencialismo, ratificado em recente plebiscito.

A Constituição de 1988 conjuga no Presidente da República a direção do Governo com a Chefia de Estado, atribuições que serão analisadas em capitulo destacado. Os Estados e Municipiem capitulo destacado. Os Estados e Municipi-
os refletem esse sistema, com as peculiaridades próprias.

\subsection{Poder Executivo Federal}

O governo, a administração do pais, é realizada pelo Poder Executivo Federal. Comparativamente à Constituição de 1967, e sua emenda nº 1/69 (conhecida como Emendão de 69), a Carta atual reduziu um pouco a esfera de atribuições do Executivo, tradicional detentor de concentração de atribuições - procurando um melhor equilibrio com os demais poderes, cuja esfera de competência foi sensivelmente ampliada, tanto o Legislativo, quanto o Judiciário.

A Constituição diz que "o Poder Executivo é exercido pelo Presidente da República, auxiliado pelos Ministros de Estado". Com propriedade, não refere o Vice-Presidente, que não exerce por si mesmo qualquer esfera de poder, mas apenas substitui o titular nos eventuais impedimentos. Mas 0 art. 76 omite referências aos diversos órgãos de administração direta ou indireta, constituidos sob a forma de autarquias, fundações públicas, empresas públicas e sociedades de economia mista. Embora alguns destes sujeitem-se ao regime juridico privado (art. 173 , inc. $\left.1^{\circ}, \mathrm{CF}\right)$, são órgãos da politica governamental, através dos quais o Estado exerce parcela de seu poder. Um dos maiores poderes da União está em imprimir a moeda (art. 21 VII, CF) permitindo-lhe o controle da economia. 


\section{a) Presidência da República}

Conjugando as Chefias de Estado e de Governo, o cargo de Presidente comporta inúmeras atribuiçōes, cuja citação fugiria aos limites deste ensaio, e é suficientemente detalhada nos diversos Comentários à Constituicão. Mas uma visa visão generica dessas atribuiçoes nào poderia deixar de criticar a competência legislativa do Presidente da República, em determinados casos. A exorbitância desse poder legislativo anômalo sujeita-se não só ao controle judicial, mas ao controle do próprio Congresso Nacional (CF, art. $49-\mathrm{V}$.

Podemos dividir as atribuiçōes do Presidente da República entre as de Chefia de Estado como as dos incisos VII e VIII, do art. 84 (CF) relacionar-se com os organismos estrangeiros e as de Chefia de Governo, como as dos incisos II, XXIII e XXV do mesmo artigo 84, tipicamente administrativas. ${ }^{4}$ Outra classificação divide os atos entre privativos e delegáveis aos Ministros.

\section{b) Vice-Presidência da República}

Eleito por cinco anos, juntamente com o Presidente da República, dentre os brasileiros natos maiores de 35 anos no exercício dos direitos politicos, o Vice-Presidente è o substituto eventual ou permanente do titular. Além das atribuições do titular durante a substituição, o Vicebuições do titular durante a substituição, o Vice-
Presidente pode ser incumbido de missões especiais, e integra os Conselhos da República de Defesa Nacional.

Nosso pais, apesar da necessidade de conter os gastos públicos, possui exacrável praxe do Vice-Presidente assumir, temporariamente, exercicio da Presidência quando o titular sai do país, ainda que por poucas horas.

A Constituição Federal só impõe essa prática para afastamentos superiores a quinze dias, com necessidade de autorização (art. 83 e 49 , III). As atuais facilidades de comunicação permitem a direção do pais de qualquer ponto do globo.

Essas mudanças simbólicas de Chefia revelam-se inúteis e extremamente onerosas para os cofres públicos. Inúteis porque os que assumem interinamente, seja por temor reverencial ao titular seja pelo temor real de que seus atos sejam retificados os expondo ao ridiculo, não tem qualquer iniciativa em termos de administração pública. Limitam-se a liberar verbas e condecoraçōes aos seus afetos, e usufruir das prerrogativas de Chefe de Estado em visitas ao seu domicilio eleitoral. Essas mudanças simbólicas oneram o erário porque, além da pompa do substituto no exercício do cargo, arcam com do cargo, arcam com aparato burocrático que acompanha a "comitiva presidencial" nas viagens.

A pobre nação brasileira sustenta dois Presidentes, embora nenhum deles esteja de fato no comando da economia e administração pública... O prejuizo é total. Esse fenômeno juridicosociológico revelou-se em toda sua extensão na

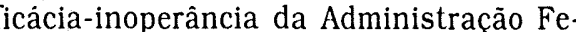
deral, capitaneada pelo Exmo. Sr. Dr. Itamar Franco que, definitivamente empossado na Presidência, continuou agindo como Vice no exercício, marcando compasso ao longo de mais de ano.

\section{c) Ministros de Estado}

Os Ministros de Estado são escolhidos (art. 87) e nomeados (art. 84-I) pelo Presidente da República entre os maiores de 21 anos $^{5}$ no exercício dos direitos políticos. Suas atribuições precipuas são colaborar com o Presidente da República no exercicio da chefia de governo na administração do Estado, com exceção do Ministro das Relaçōes Exteriores. 0 art. 87, parágrafo único, da CF, refere, em linhas gerais, os atos dos Ministros de Estado, remetendo à legislação ordinária, que cria e regula atuação dos Ministérios. Na Emenda Constitucional no $1 / 69$ 0 Presidente possuia iniciativa de criar e extinguir Ministërios, que hoje passou à competência do Congresso Nacional.

Ao falar dos atos e atribuições dos Ministros de Estado, deve-se referir a classificação dos atos do Presidente da República em privativos e delegáveis, já que estes são os que podem ser atribuidos aos Ministros ${ }^{6}$

O Prof. José Afonso da Silva ${ }^{7}$ sugere destacar das funções de Chefia da Administração Federal, diretamente atrelada à orientação desta, sub-classe que incluiria justamente os atos do Presidente da República delegáveis aos Ministros de Estado, acrescidas do dever de prestar contas dessa administração (art. 84 - XXIV). Já os Ministros "prestam contas" ao Presidente atravês de relatórios anuais (art. 87 - III), e assinam os atos e decretos referentes à área de competência de seus Ministërios.

\section{d) Órgãos da Administração Direta e
Indireta}

Além dos Ministérios, compõe a administracão federal diversos organismos instituidos sob forma de Autarquias e Fundaçōes Públicas (ambas pessoas juridicas de Direito Público); e de Sociedades de Economia Mista e Empresas Públicas (ambas entidades de direito privado), $\mathrm{cu}$ jos dirigentes são de livre escolha ${ }^{8}$ do Presidente da República e Ministros de Estado, nos termos das Leis que constituem e organizam cada uma dessas entidades.

\section{e) Conselho da República}

Órgão da Chefia de Estado, o Conselho da República compõem-se do Presidente da República e Vice, dos Presidentes do Senado e Câmara e do Ministro da Justiça, que também integram o Conselho de Defesa Nacional. A essa autoridades somam-se os lideres da maioria e minoria da Câmara e do Senado, mais seis cidadãos com mais de 35 anos, com mandato de 3 anos, vedada a recondução, sendo dois escolhidos pelo Presidente, e dois escolhidos por cada Casa do Congresso.

O Presidente da República dirige suas reuniões, para as quais pode convocar outros Ministros quando a pauta envolver questões relacionadas à respectiva pasta.

A esse órgão de consulta compete opinar sobre intervenção; estado de defesa e de sítio; questōes, em geral, "relevantes para a estabildade do Estado". Esse órgão teria extrema importância caso tivesse sido aprovado o sistema parlamentarista, conjugando entendimentos ambos poderes envolvidos com 0 Governo. ${ }^{9}$

\section{f) Conselho de Defesa Nacional}

O CDN (Conselho de Defesa Nacional) tam bém é órgão consultivo da Chefia de Estado. Dele participam, além dos já mencionados componentes do Conselho da República (Pres. da Rep. Vice, Pres, do Senado e Câmara e Ministro da
Justiça), os Ministros Militares, das Relaçōes Exteriores e do Planejamento.

Diferentemente do Conselho da República criado em 1988 para opinar sobre questões internas, o Conselho de Defesa Nacional já existia anteriormente, embora com outro nome, CSN (Conselho de Segurança Nacional). Hoje, ele é mais consultivo, enquanto o CSN era um órgão de execução da politica de segurança.

Embora a CF não seja clara, a doutrina entende que a consulta ao CDN é obrigatória para os atos especificos do parágrafo primeiro, do art. 91 , sendo relevante para os atos do inciso I ouvir os Ministros Militares e das Relações Exteriores; para os atos do II devem ser ouvidos os Presidentes da Câmara e do Senado devido à supressão das garantias constitucionais decorrentes. Lamentavelmente, os Ministros das Minas e Energia não tem assento no Conselho, pois lhes competiria opinar sobre a hipótese do art. 91, parágrafo primeiro, inc. III e, pelo que consta do texto constitucional a $\mathrm{CF}$ é omissa a respeito quando trata do Conselho de Defesa Nacional, embora o final do "caput" do art. 91 sugira que os enunciados são membros "natos", abrindo perspectivas para que o CDN seja integrado por outros membros. ${ }^{10}$

\section{DISCRICIONARIEDADE ADMINISTR ATIVA} VERSUS IMPA RCIALIDADE JURISDICIONAL

Ao falar das atribuições do Poder Executivo é importante destacar a discricionariedade administrativa, que caracteriza esse poder estatal. Diferentemente dos atos judiciais, exercidos por órgão imparcial, e onde toda decisão deve ter fundamentos de direito sob pena de nulidade (art. 93, inc. IX, da CF), a administração pública possui uma maior liberdade de ação, chamada de discricionariedade administrativa, permitindo que o poder executivo cumpra sua função politica de administrar.

Na atividade administrativa, o poder age no próprio interesse de bem administrar os órgãos de atuação do Estado, com o que os seus dirigentes granjearão o respeito e admiração do eleigentes gran
torado.

Na atividade jurisdicional o julgador não pode nem mesmo ter a expectativa de agradar às partes ou a quem quer que seja, qualquer quebra 
da postura eqüidistante compromete o resultado da atividade estatal como bem demonstrou Chiovenda". Ao procurar não prejudicar a parte de quem è desafeto, termina beneficiando-a Do contrário, procurando ser imparcial com os afetos, é rigoroso demais. Esse inolvidável mestre italiano estabeleceu como pressuposto à definição da Jurisdição como "atividade estatal que realiza o direito positivo" o caráter substitutivo dessa atividade, onde as partes são substituidas por um um órgão estatal imparcial para bem compor o litigio.

Mas a peninsula efervescia com grandes pensadores iniciando-se longo processo dialético nas investidas de Carnelutti ${ }^{12}$ e seu conceito de lide.

Allorio $^{13}$ desenvolveu a idéia originalmente de Calamendrei ${ }^{14}$ quanto à pedra de toque que seria a coisa julgada, tese que floresceu com a adesão, dentre outros, de Couture $^{15}$ e, no Brasil, de Frederico Marques, Arruda Alvim, Lopes da Costa, e muitos outros. Essa sucessão de tesouros de direito processual fez com que a idéia, verdadeiramente brilhante de Chiovenda, da substitutividade, muito contestada em face do processo penal e da jurisdição voluntária ${ }^{16}$, só muito mais tarde fosse alcançada em sua genialidade pela obra de Gian Antonio Micheli.

Micheli, em memorável ensaio Per una revisione della nozione di giurisdizione voluntaria ${ }^{17}$, dá-nos conta das alturas alcançadas no pensamento de Chiovenda. O mesmo diapasão è encontrado em J. J. Calmon de Passos ${ }^{18}$, reprodu zindo a lição de Marco Tullio Zanzucchi ${ }^{19}$.

Chiovenda, quando falava em jurisdição como atividade substitutiva, queria deixar claro que o juiz substituia as partes para julgar de forma imparcial por ser um terceiro, totalmente desinteressado no resultado ${ }^{20}$. A imparcialidade e 0 desinteresse do estado-juiz na solução do litígio são indispensáveis na atividade jurisdicional, ao passo que a parcialidade e o envolvimento/interesse nos resultados são caracteristicas da atividade administrativa.

Mas justamente em razão do envolvimento do administrador e de seu interesse no resultado de sua atividade, é que a discricionariedade sofre limites. Os atos devem respeitar os principios da legalidade, impessoalidade, moralidade e publicidade, a serviço do bem comum, expressos no no art. 37, caput, da CF, aos quais a doutrina acrescenta, com respaldo na jurisprudência, a vedação do "desvio de poder", derivado do principio da legalidade; o principio da "razoabilidade", de inspiração norte-americana e os principios gerais de direito.

\subsection{Medidas Provisórias}

As Medidas Provisórias foram incorporadas em nossa Constituição a partir do modelo Parlamentarista, prevendo a adoção desse sistema. Adotada como alternativa ao famigerado decreto-lei, revelou-se mais danosa.

Como no dito popular, pior emenda que o soneto.

Enquanto os decretos-lei possuiam limites ao seu emprego, as novas Medidas Provisórias ampliaram 0 leque de hipóteses de utilização para qualquer caso onde, a critério exclusivo do Presidente de República, haja "relevância e urgência". A limitação temporal revelou-se inócua. A cada trinta dias, o Executivo edita nova MP de texto igual ou semelhante à anterior

Esse emprego abusivo de MP, centenas e centenas, permitiu que o Executivo usurpasse a função básica do Poder Legislativo, praticamente inviabilizando a atuação dos Parlamentares, "soterrando" o Congresso com uma avalanche de sucessivas MP's cujo exame obrigatório compromete o tempo util dos representantes do Powo que, passados 5 anos da edição da CF de 1988 . ainda não havia regulamentado nem um décimo dos artigos da Constituição Federal que exigiam leis complementares ou ordinárias. A inoperância do Legislativo assoberbado pelo expediente, "justifica" mais e mais atividade legislativa anômala do Poder Executivo, sendo necessário por fim a tal expediente, antes que se eternize.

\subsection{Controle Judicial}

A CF de 1988 ampliou o controle judicial da administração pública, permitindo ao Judiciário anular atos administrativos contrários ao interesse público, mesmo que se trate de acoher diversos principios - como demonstrou a professora Dra. Maria Sylvia Zanella di Pietro ${ }^{21}$, que dia 27 de setembro de 1993, a convite do Procurador Geral do Estado do RGS, Dr. Gabri- el Pauli Fadel, desceu em Porto Alegre especialmente para brindar os Procuradores do Estado mente para brindar os Procura
com uma conferência especial.

A persistir a acomodação do Parlamento em A persistir a acomodação do Parlamento em
ace do abuso, pelo Executivo, de Medidas Provisórias, o único mecanismo que restará para refrear essa usurpação de poder será o Judiciário.

Os juizes que já possuem casos demais para julgar, serão convocados a decidir sobre a conveniência da edição da norma diante dos pressupostos de "relevância e urgência" impostos pela Constituição Federal (art. 62).

O controle judicial do uso abusivo de Medidas Provisórias poderá ocorrer em todos niveis de controle da constitucionalidade dos atos legislativos, desde o controle difuso, caso a caso, ou mediante Ação Direta de Inconstitucionalidade veiculada por algum(ns) dos legitimados (art. 103). E não será demasia lembrar da possibilidade do Estado ser acionado pelo dano provocado pelo ato legislativo. ${ }^{22}$

\subsection{Política e Poder}

O Estado é uma entidade abstrata, com objetivo ideal de alcançar o bem comum. Sendo dirigida por seres humanos, cumpre evitar que esses condutores desviem-se (ainda que involuntariamente) da função estatal. Por isto existem as Constilui tem as Constiluic Lestatal, repartindo os poderes. $\Lambda$ s atribuições do Poder Executivo devem ser exercidas para bem comum. sem desvio de função. E se o Poder Legislativo tem suas funçōes usurpadas ao ponto de fica indefeso diante do uso abusivo de Medidas Provisórias, restará sempre o Judiciário atento para coibir os abusos, com a imparcialidade caracteristica dos órgãos jurisdicionais.

\section{NOTAS DE REFERÊNCIA}

1 Ensaio elaborado a partir da prova escrita realizada no concurso de provas e titulos para o cargo de Professor de Direito e Legislação na Ufrgss onde o autor foi aprovado com média 9,33 . Um trecho deste trabalho, e antes das revisóes e ampliaçōes, foi publicado com o nome de Controle jurisdicional do abuso de medidas provisórias na "Adv" Advocacia Dinâmi28/95, 14 de julho de 1995, p. 305-307.
0 recente "impeachment" de Fernando Collor foi caso tão excepcional, que so vem confirmar a regra. Rui Barbosa, "Oração no Colégio Anchieta", 1903, "apud" Alcides de Mendonça Lima, "A primeira Cons. tituição Republicana do Brasil", in: Revista da Ajuris, 51 , p. 20 "usque" 30.

Nas atribuiçōes de Chefia de Governo poderiamos incluir, ainda, os dois incisos I, III, IV, V, VI, XI, XIV, XV, XVI, XXIV do art. 84 da Constituição Federal, e as das alineas a), b), c), d) e e), do inciso segundo, do parágrafo $1^{\circ}$, do art. 61 (CF), embora algumas de forma controvertida. E o caso do veto (art. $84-V$ ) onde o Presidente deve agir em defesa da Consticuiça - embora esse instituto tenha muito maior uso poltico. Para dem nu quis pures do art 84 com maior ou menor grau, são atos de Chefia de Estado.

A a sa $\mathrm{CF}$ reduziu o limite de idade dos Ministros, que era de 25 anos, para 21 anos.

que era de 25 anos, para 2 atos do mencionados no art. 61 , parágrafo primeiro, bem mencionados no art. 61, paragrafo pr, XI, XII, XIV, XV, XVI, XVII, XVIII, XIX, XX, XXi, XXII, XXIII, XXIV e XXVI. Os demais, são atos delegáveis aos Ministros de Estado.

7 Prof. José Afonso da Silva, Curso de Direito Constitucional Positivo, RT, 1989, p. 471

A única exceção à livre escolha do executivo são as universidades onde há eleição dos reitores e direto-

res das unidades.
$\mathrm{O}$ Conselho da República foi uma inovação da $\mathrm{Co}$ missão de Sistematização visando adequar a no Carta ao almejado Sistema Parlamentarista.

10 Diferente no Conselho da República, onde o Presidente poderia convocar outros Ministros (art. 90 parágrafol, a $\mathrm{CF}$ é omissa quanto a tal possibilidade
no $\mathrm{CDN}$.

11 Giuseppe Chiovenda, Princippi di diritio processuale civile, parágrafo segundo, ou na edição brasileira das Institutuçoes de Diretto Processual Civil, na excelente
traduçâo anotada por Liebman.

Frances Carnelutiti Sistema dic

a di diritto processuale Five

\& pro Alo, La cosa giudicata rispetto terzi, 1935 \& problemas del derect
nhola, Buenos Aires.

14 Piero, Buenos Ares. nistración en la sentencia civile, nos Estudios sobre proceso civit, tradução argentina de 1961, p.48.

15 Eduardo Couture. Fundamentos del derecho procesual civil, 1958, p. 42.

16 No processo penal, e mesmo no processo civil na jurisdição denominada de voluntária certos juristas alegam dificuldades de vislumbrar a substitutividade. Isso decorre de uma análise superficial do fenómeno que, em profundidade, revela justamente no terceiro imparcial o aplicador da lei conciliando confito entre 0 interesse privado ofendido (no processo penal) ou tutelado (na jurisdição voluntária), 
que motivam a proibição da vingança privada naquele, e o revestimento de formalidades certos atos, nestes. Para descobrir um novo enfoque possibilitando vislumbrar a natureza substitutiva da jurisdição graciosa e penal, veja nosso trabalho Chiovenda, jurisdição voluntária e processo pe nal publicado na Revista de Processo, RT, v. 81, janeiro-marco de 1996, p. 233-239, bem como Revis ta Trabalho \& Processo ou Trabalho e Doutrina, Sa-

17 Gian Antonio Micheli, Per una revisione

di giurisdizione voluntaria Rivista 1947 v I traduzido para o espanhol e re publicad. . . p. 31 , nos Estudios de derecho procesal civil, v. IV 1970 8 J. J. Calmon de Passos Da jurisdiçäo 1957, p. 18 19 Marco Tullio Zanzucchi Diritto processuale civile

20 Por isto que quando das polèmicas em torno do SF os juizes que eram mutuários do sistema conside- ravam-se suspeitos para decidir tais causas pois, como mutuarios, possuiam interesse (ainda que re motol de que prevalecessem as teses que reduziam as prestações.

21 Maria Sylvia Zanella di Pietro, Discricionariedade Administrativa na Constituição Federal de 1988, tese de livre-docência na USP, aprovada com grau 10 pelos 5 membros da banca examinadora composta, entre outros, por José Cretella Jr., e publicada pela Atlas em 1991.

22 Cesar Viterbo Matos Santolim, A responsabilidade Civil do Estado, trabalho apresentado no Mestrado em Direito da Ufrgs, e publicado na Revista Estudos 55, p. 45.54 Fac. de Direito da Unisinos, v. 22, $\mathrm{n}^{6}$ 5. p. 45.54, conlira tambèm Luiz R. Nuñes Padilla, Responsabildade Civil do Estado por Ato Jurisdi(COAD) 1993, p.

\section{A Constituição de 1988 e a Judicialização da Política}

\author{
Manoel GonÇalves Ferreira Filho
}

Professor Titular de Direito Constitucional da Faculdade de Direito da USP.

Doutor em Direito pela Universidade de Paris.

Professor Visitante da Universidade de Aix-en-Provence (França).

Membro da Comissão Executiva da

Associação Internacional de Direito Constitucional

Presidente do Instituto "Pimenta Bueno"

(Associação Brasileira dos Constitucionalistas)
1. Tanto no Brasil como no estrangeiro preocupam-se juristas e politólogos com o fenômeno da judicialização da politica. Aqui, já é ele. há certo tempo, assunto de debate tanto no meio jurídico quanto no politico ${ }^{1}$

Lá fora, o interesse pelo tema levou à publicação de um número especial da Internationa Political Science Review, intitulado "The judicialization of politics"

\section{I - O CONCEITO DE JUDICIALIZAÇÃO}

2. Entende-se por judicializacão da politica a tendência a atribuir, ou submeter, aos tribunais judiciários a decisão de mérito a respeito de açōes administrativas ou normas obrigatórias. Ou seja, decisões "politicas", porque concernentes a 0 interesse da comunidade.

Talvez melhor fosse falar em judicialização do político, pois a förmula judicialização da politica traz a impressão errônea de que a disputa política é que é judicializada, quando é a ação governamental que cai nas mãos dos juizes. Entretanto, a experiência mostra que não adianta lutar contra expressōes difundidas, mormente quando elas soam bem. É o caso da expressão empregada.

Em outras palavras, consiste a judicializa cao em atribuir ao Judiciário decisōes que, no termos da doutrina clássica da separação dos poderes, incumbiriam ao Executivo ou ao Legislativo. Decisões estas de caráter político, eis que afetam o destino da comunidade (a polis), ou importam em orientar em direção a objetivos determinados a máquina governamental, em decorrência de uma visão do bem comum.

Num sentido mais fraco, todavia, a expressão é empregada para designar a adoção de procedimentos próximos aos típicos da Justiça para a preparação da tomada de decisões por órgãos administrativos ou legislativos. Assim, nos Parlamentos, os hearings, em que se ouvem interessados na decisão a ser tomada, nas administrações, o convite aos interessados para que se manifestem, como se faz às vezes no caso de operaçōes de renovação urbana, de desapropriações para grandes obras, de obras que possam afetar o meio ambiente, etc. Não é esta judicialização, entretanto, que nos preocupa neste trabalho.

\section{II - A JUDICIALIZAÇ̃̃O NO ESTRANGEIRO}

3. Nos Estados Unidos, a judicialização no sentido forte vem de longe. Talvez por isso seja esse pais o lugar em que aparece mais avança$\mathrm{da}^{3}$

Está ela intimamente ligada à judicial review, ou melhor, um alargamento do escopo da mesma. De fato, a Suprema Corte, de 1954 para cá, embora com menor intensidade nos últimos anos, vem, ao fulminar atos ou normas por inconstitucionalidade, afirmando padrões positivos que devem ser obrigatoriamente seguidos. 